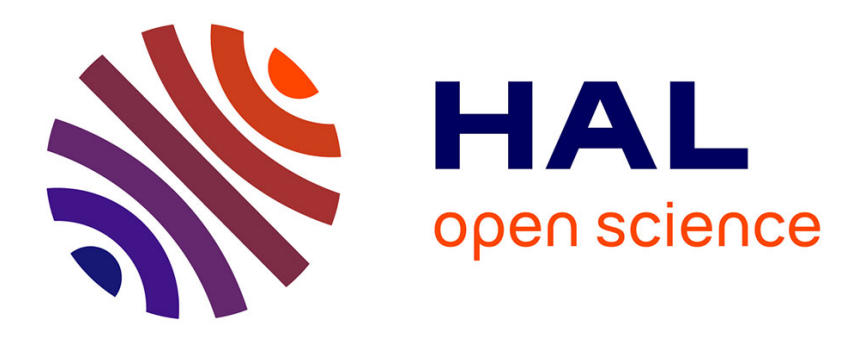

\title{
Rebound effects and ICT: a review of the literature Cédric Gossart
}

\section{To cite this version:}

Cédric Gossart. Rebound effects and ICT : a review of the literature. ICT innovations for sustainability, 310, Springer, pp.435 - 448, 2015, Advances in intelligent systems and computing, 978-3-31909227-0. 10.1007/978-3-319-09228-7_26. hal-01258112

\section{HAL Id: hal-01258112 \\ https://hal.science/hal-01258112}

Submitted on 18 Jan 2016

HAL is a multi-disciplinary open access archive for the deposit and dissemination of scientific research documents, whether they are published or not. The documents may come from teaching and research institutions in France or abroad, or from public or private research centers.
L'archive ouverte pluridisciplinaire HAL, est destinée au dépôt et à la diffusion de documents scientifiques de niveau recherche, publiés ou non, émanant des établissements d'enseignement et de recherche français ou étrangers, des laboratoires publics ou privés. 


\title{
Rebound Effects and ICT: A Review of the Literature
}

\author{
Cédric Gossart \\ Institut Mines-Télécom/Télécom École de Management, Evry Cedex, France \\ Cedric.Gossart@telecom-em.eu
}

\begin{abstract}
This paper presents a critical review of the literature on the rebound effects generated by information and communication technologies (ICT). Following a discussion of the types of general rebound, including direct, indirect, and economy-wide, the literature on ICT-related rebound effects is critically assessed. The chapter suggests ways of overcoming rebound and lays out promising avenues of research to better understand and tackle rebound effects in ICT.
\end{abstract}

Keywords. Rebound Effects, ICT, Resource Efficiency

\section{Introduction}

Between 1982 and 2012, while final energy intensity in France decreased by one third, final energy consumption increased by $15 \%$, from 134 to 154 Mtoe [1]. The transportation sector also witnessed important energy efficiency gains. For example, the fuel consumption of a medium-range car dropped from 8.3 to $6.71 / 100 \mathrm{~km}$ between 1990 and 2012, and $\mathrm{CO}_{2}$ emissions of new average cars also dropped from 175 to $124 \mathrm{gCO}_{2} / \mathrm{km}$. In the same period, the mileage per medium range car remained stable at around $13,000 \mathrm{~km} / \mathrm{y}$. These results should have delivered energy savings to the French economy, but the exact opposite happened: the final energy consumption of road transportation increased from 32 to $36 \mathrm{Mtoe}$, and its $\mathrm{CO}_{2}$ emissions increased by $10 \%$. Despite energy efficiency improvements, overall energy consumption and pollution increased, notably because the number of cars increased from 24 to 32 million, providing evidence of a "rebound effect." One would not be blamed for questioning, like Herring [2-3], whether energy efficiency measures do in fact deliver energy savings. As explained in the next section, information and communication technologies (ICT) are often used to improve energy efficiency but are subject to rebound effects. Large public and private investments are made every year to leverage ICT to improve energy consumption and other types of efficiency such as labor productivity. But if the rebound effects associated with ICT are high, those gains will be absorbed and the environmentally-driven investments will fail to meet their objectives.

The purpose of this paper is to clarify the rebound effects related to ICT, including energy-related effects. To this end, Section 2 defines rebound effects, and Section 3 presents the rebound effects that are associated with ICT. The conclusion offers some ways for avoiding ICT-related rebound effects and points to future lines of research.

This Accepted Author Manuscript is copyrighted by Springer. The final publication will be available via http://link.springer.com/bookseries/11156 by end of August 2014. Suggested citation: Gossart, C.: Rebound Effects and ICT: A Review of the Literature. In: Hilty, L.M., Aebischer, B. (eds.) ICT Innovations for Sustainability. Advances in Intelligent Systems and Computing 310. Springer International Publishing (2014, in press) 


\section{What Are Rebound Effects?}

\subsection{Definitions}

In the $19^{\text {th }}$ century, the industrial revolution supported England's economic wealth and political power. Domestic coal was key to maintaining this power and there were great fears regarding the growing scarcity of this cheap local fuel. England was consuming massive amounts of coal, and much of it was wasted by inefficient mining and processing. To prevent this core resource from being prematurely exhausted, engineers invented solutions to reduce coal waste by improving mining and processing efficiency. Would English coal resources last longer thanks to these energy efficiency innovations? A negative answer seldom heard at the time was voiced in a book entitled The Coal Question, in which the economist William Stanley Jevons claimed in that "technological efficiency gains (...) actually increased the overall consumption of coal, iron, and other resources, rather than saving them" [4, p. 9]. In his formulation of the "Jevons' paradox," Jevons demonstrated that contrary to their primary objective, efficiency policies were actually counterproductive and were leading to resource overuse [5]. Jevons believed that "the present generations are allowed to use intensively ore resources to the extent they transform them in wealth for future generations" [6, p. 100].

It was more than a century before energy economists coined the expression "rebound effect" to characterize the negative side effects of efficiency policies and strategies that ended up taking back the environmental gains they had permitted. For them, the term "rebound effect" dates back to Khazzoom [7] and characterizes "improvements in the technical efficiency of energy use" that had a smaller energy-saving effect than predicted by engineers [8]. Indeed, efficiency gains achieved when manufacturing a product or providing a service reduce their costs. As a consequence, its price decreases and demand for it increases. If efficiency gains are indeed reported at the micro level of single products, the macroeconomic picture suggests that more resources have actually been used, for example because the lower price of single products has boosted their sales or because the more efficient single product has been used very intensively. For example, a company using energy-efficient servers will reduce its data storage costs, which will enable it to buy more servers and to use them more intensively, directly impacting its electricity bill. In analyzing the relationships between ICT and the environment, Hilty emphasizes that they can enable positive environmental changes but also negatives ones [9]. Based on an OECD report [10], the author distinguishes three levels of effects of ICT on the environment: $1^{\text {st }}$ order effects (direct effects of ICT caused by their physical production, use, and disposal), $2^{\text {nd }}$ order effects (impacts of ICT on other sectors), and $3^{\text {rd }}$ order effects (structural ones), which include rebound effects. 
Rebound effects have also been discussed in other disciplines such as psychology, as in the case of "stereotype rebound." Another psychological rebound effect occurs when ecotechnologies make consumers feel good and encourage increased consumption of greener products [12]. From an economic perspective, consumers buy a given product because it "maximizes his/her utility": it serves a purpose or need, which makes the consumer happy and satisfied for a given amount of money. The various needs that people seek to satisfy have been described in a simple manner by Maslow's "hierarchy of needs," which represents people's needs in a pyramid starting with basic needs at the bottom: physiological needs, safety needs, love and belonging, esteem, self-actualization. Once the first two basic needs have been satisfied, people seek to satisfy more elaborate ones such as the need to belong to a community or to be esteemed by their peers. Consuming greener products can contribute to these needs because it makes individuals feel that they belong to a community of people who care about the environment, and that they are esteemed by other people because they adopt responsible consumption patterns.

\subsection{Categories of Rebound Effects}

In a seminal paper in which he recalls the history of the concept and clarifies its categories, Sorrell explains the three categories of energy-related rebound effects [8], which were already present in Jevons' book (as underlined by Missemer [6]). They are "typically expressed as the percentage of potential savings taken back from the maximum efficiency improvement expected" [12, p. 6].

The first category includes direct rebound effects, which have been extensively analyzed by economic theory [13-15]. In this case, lower energy cost induces price reductions that trigger an increase in the demand for the cheaper good (e.g. if washing machines need less power, consumers can afford to wash more frequently). From earlier work, Sorrell cites the example of the Bessemer process, which enabled metallurgical companies to achieve their greatest energy savings of all times, while at the same time leading to large increases in steel demand that would not have been seen before that innovation [8]. Here, the money saved thanks to energy efficiency gains was reallocated to consume more of the same product. For example, throughout the second half of the $20^{\text {th }}$ century, in the US manufacturing industry there is evidence of a $24 \%$ rebound effect, meaning that energy efficiency gains had gone hand in hand with a $24 \%$ increase in energy demand [16]. It is hard to compare evaluations of rebound effects since they vary with the methodology and data employed. Hence, some authors disagree with Jevons' standpoint, claiming that rebound effects have been small over the 1970s and 1980s, and that during this period "most of the improvements in energy efficiencies led to reductions in energy intensities" [17, p. 367]. Others underline that if total resource consumption grows while efficiency improves it "does not necessarily demonstrate that resource consumption grows because of im-

1 "Stereotype rebound refers to the ironic finding that active efforts to avoid thinking about people in a stereotypical manner can backfire and subsequently lead to increased stereotypical thinking and prejudiced behavior." [11, p. 111]. 
provements in efficiency" [18, p. 21]. However, Bentzen suggests an order of magnitude for the rebound effect that ranges between 0 and $50 \%$ in relation to consumers, with a smaller effect for firms [16]. At the upper margin, this would imply that if technological energy efficiency gains are predicted to be $100 \mathrm{MW}$ by engineers, they are actually only $50 \mathrm{MW}$. Half of the expected energy savings are absorbed by rebound effects. The author also reports a study showing that in the Netherlands, up to $30 \%$ of projected efficiency gains could be absorbed by an increased demand for energy services [13]. Although these estimates are not very precise and vary across time, countries or sectors, they may be useful to firms and policy makers as an indication of how much they should reduce their expectations of the savings generated by energy efficiency measures. For example, in calculating the return on investment of an insulation program, a government agency could use a discount rate of $30 \%$ to account for potential rebound effects in order to obtain more realistic energy saving figures. This rate would vary across sectors; for example, rebound effect estimates in the UK industrial sector are about $15 \%$, and they range between 20 and $60 \%$ for US energy-intensive sectors [18].

The second category concerns indirect rebound effects: When a resource is used more efficiently and its price goes down, it induces the consumption of other commodities (e.g., consumers buy extra DVD players for the money they saved due to an energy-efficient product). In this case, households use their increased remaining income to buy other energy-consuming products or services. For example, if a family saved money by insulating its apartment, it might use the savings to fly to a remote holiday location instead of taking the train to a closer one. Overall, the financial gains from insulation-driven energy savings would not generate environmental benefits.

A third category concerns economy-wide rebound effects, which appear when declining energy prices induce a reduction in the prices of intermediate and final goods throughout the economy and cause structural changes in production patterns and consumption habits. For example, cheaper gasoline enables people to live further away from their workplace by making it less expensive to drive longer distances to work. These effects are the aggregated result of both direct and indirect rebound effects and can be expressed as a "percentage of the expected energy savings from an energyefficiency improvement" [8, p.1457]. If this percentage reaches $100 \%$, it means that "the expected energy savings are entirely offset, leading to zero net savings for the economy as a whole" (ibid.). These savings "backfire" when the rebound exceeds $100 \%$, which means that the overall energy consumption actually increases after energy saving measures (ibid.).

The rebound effects defined here refer to "pure" energy efficiency gains; i.e., energy efficiency productivity, with no gains in other resource productivities and no gains in labor and/or capital productivity (including convenience). One must be careful speaking of a rebound effect in these cases. In practice, technological change generally produces a bundle of improvements, of which the energy efficiency gain is just one such improvement. Indeed, such a change can become so popular that it produces other improvements that can be considered "collateral benefits." Hence, these benefits can give the demand for the improved technology a huge boost and lead to economywide rebound effects higher than $100 \%$. As a consequence, a technology that leads to 
efficiency gains on the micro level might actually lead to efficiency losses on the macro level. In order to avoid this confusion, a distinction can be made between pure energy efficiency improvements and technological changes that include energy efficiency improvements.

\section{Rebound Effects and ICT}

\subsection{ICT and Efficiency}

ICT include both hardware and software technologies. Historically, they are among the most prominent general purpose technologies, such as steam, electricity, and internal combustion, since they generate wide-ranging impacts across all sectors, including economic, social, and environmental effects [19-20]. General purpose technologies are pervasive (spreading to most sectors), improve over time, spawn innovation (making it easier to invent and produce new products or processes), and continually lower costs for their users [21]. Therefore, the efficiency gains enabled by ICT diffuse across all sectors, as do their related rebound effects. There are many ways in which ICT can contribute to energy efficiency [22]. They can reduce their own energy consumption, enable energy savings in other sectors such as buildings, transportation, and lighting control, contribute to energy saving awareness, and so on. Consequently, they are the focus of ad hoc policies that seek to support these contributions, such as the European energy efficiency plan [23] or the Smart 2020 initiative [24]. The former does not mention rebound effects, but the latter underlines that in the case of ICT, "prevention of the rebound effect requires an emission-constraining framework," suggesting that energy efficiency technologies alone are not enough to foster energy savings [24, p. 2].

In order to avoid rebound effects that would absorb the positive contributions of ICT to energy savings, rebound effects related to ICT must be identified and evaluated. Unfortunately, few studies have measured rebound effects related to ICT. For example, Energy Policy's 2014 special issue on "Energy efficiency for a more sustainable world" does not contain a single paper on rebound effects, and the term is not even mentioned in its editorial [25]. A study on Korea even shows that when they are not geared towards reducing energy consumption, ICT investments can contribute to increased electricity intensity, because they induce the replacement of less laborintensive inputs with more electricity-intensive ones [26]. This is consistent with Binswanger who argued that when production costs are dominated by wages and energy prices are low, labor will tend to be replaced by machines [27]. Since machines usually consume more energy than human workers doing the same task, low energy prices will encourage increases of firms' energy consumption. Sorrell argues that this is also the case with household appliances such as washing machines or dishwashers [28]. It might also be true for ICT that replaces manpower, as in the case of electronic messaging that partly substitutes for written letters sent by mail. The comparison of traditional paper-based media with electronic media with regard to sustainability is discussed in detail in the chapter by Coroama et al. [29] in this volume. 


\subsection{Direct Rebound Effects}

Direct rebound effects appear when technological change enables an improvement in the efficiency with which some output can be produced from a resource, whose demand then increases as prices go down, thereby absorbing the resources saved by efficiency gains. As a consequence, more of the same resource is consumed.

In ICT, the optimized output is information: Moore's law formalized efficiency gains enabled by technological change in microprocessors. This generated rebound effects related to key resources such as time and raw materials. For example, since microprocessors are getting continuously smaller, each of them requires less material to be built [9]. But as a consequence, their prices drop, their demand explodes, and new models quickly offset slower ones. This contributes to the obsolescence of computers, for example, since only new ones are powerful enough to host heavier operating systems. Many users would notwithstanding have been satisfied with a PC fitted out with an older processor, since they do not need quadruple core processors to write emails and surf on the Internet. Because of efficiency gains at the level of ICT components, ICT products are made obsolete, which wastes the resources that could have been saved thanks to these efficiency gains. In the end, consumers find themselves with over-equipped machines whose processors remain in a "busy waiting" state most of the time [9]. The historical development of the power consumption by ICT components is discussed in detail in the chapters by Aebischer and Hilty [30] and Kaeslin [31] in this volume.

Moreover, even if a product is small its energy intensity is often higher than that of larger products such as cars or refrigerators [32]. And this is likely to worsen with ubiquitous computing that will connect a multitude of objects to the Internet such as household appliances, wearable devices, and other smart labels, since this makes intensive use of network infrastructures by automatically generating data transfer [33]. New cars will also contribute to information overload, since "high-end functions like autonomous driving or driver assistance systems are likely to have even higher requirements for data throughput and quality" [34, p. 281].

Rebound effects caused by ICT miniaturization are exemplified by the case of Switzerland, where between 1990 and 2005 the average physical mass of a mobile phone was reduced by a factor of 4.4, while the total mass of all phones in Switzerland increased by a factor of eight, because the number of users exploded. This is an example of what has been termed the "miniaturization paradox" [9]. The underlying mechanism here may be that while ICT shrinks, MIPS per dollar increase even faster: "processing power is getting cheaper faster than it is getting smaller!" [9, p. 95]. One might argue that smaller devices require smaller batteries, yet this type of efficiency gain might be offset because devices multiply (pervasive computing enables a large number of components to be used in parallel), but also because those devices are never turned off and use energy-consuming Internet services. Another example of direct rebound effects caused by miniaturization is small RFID readers, which enable wireless short-range communication. As their price declines they multiply, which "will result in a growing stock of always-on radio transmitters whose transmitting power of up to 2 watts must be powered by mains adaptors" [33, p. 835]. 
Miniaturization also helped increase data centers' efficiency, enabling servers to grow in size and functionality. Such efficiency gains, also achieved through virtualization, ${ }^{2}$ helped reduce the costs of information storage and enabled the deployment of cloud services, which permitted multipoint information access. As a consequence, demand for data storage space skyrocketed: in 2011, all recorded data in the world amounted to $1.8 \mathrm{ZB}$ (1.8 x $10^{21}$ bytes) [35], and from 1986 to 2007 worldwide computing capacity grew five times faster than economic growth [36]. These developments, largely enabled by miniaturization, required a lot of energy. Indeed, "A modern supercomputer usually consumes between 4 and 6 megawatts - enough electricity to supply something like 5000 homes" [37, p. 50].

Finally, direct rebound effects were also identified by archivists. Confronted with increasingly large collections, they had to use increasingly sophisticated archival practices and technologies, which eventually led to higher costs in terms of time and resources. For example, archiving innovations did enable repositories to solve their backlog problem. But "once this newly found efficiency has been put into practice, it follows that the repository will seek out even more acquisitions to further its mission as a collecting repository and the new efficiency would actually cause an overall increase in the holdings of a repository" [38, p. 44].

\subsection{Indirect Rebound Effects}

Indirect rebound effects appear when a resource is used more efficiently and the prices of the goods or services produced from this resource go down, which induces an increase in the consumption of other resources. Because ICT are general purpose technologies, this type of rebound is particularly documented for several sectors where "savings from efficiency cost reductions enable more income to be spent on other products and services" [12, p. 6]. As a consequence, more of other resources is consumed.

In the area of e-learning, Herring and Roy have studied the environmental impacts of three higher education delivery systems [39]. They concluded that "electronic delivery does not result in a reduction in energy or $\mathrm{CO}_{2}$ emissions compared to printbased distance learning, due to rebound effects, e.g. in use of computers and home heating." (ibid., p. 525) As for Caird et al., their study of 30 higher education courses in campus-based and distance education systems in $15 \mathrm{UK}$ institutions revealed that, despite rebound effects, online teaching did lead to dematerialization [40].

Because it uses ICT intensively, telework is also subject to rebound effects. For example, telework can also lead to longer commutes when physical presence in the office is required, since employees might decide to live further away from their workplaces if they know that they will be able to telework. According to Hoogeveen and Reijnders, "the indirect effects associated with increased buying power and the rebound effect on transportation following from freed travel time greatly exceeded direct energy efficiency gains" [41, p. 542].

2 Virtualization enables one server to host multiple virtual servers by using computing resources that are not being used at their maximum capacity. 
Other indirect rebound effects can occur with e-commerce. But although some authors mention rebound effects as one of the side-effects of e-commerce, they do not mention any evaluation [42-43]. Only one of them argues that "teleshopping generates additional delivery transport" [44, p. 296].

In the case of transportation, Hilty et al. see strong rebound effects "whenever ICT applications lead to time or cost savings for transport" [45, p. 1618]. For example, ICT can help drivers find a parking place more quickly [46], [47]. Although this avoids wasting gasoline, it also makes it easier for people to use their car in the city and might increase overall traffic in the long run. The same consequence can ensue from ICT-based traffic management systems that reduce traffic jams. Fluidifying traffic might provide incentives for non-drivers to start using a car because it is less time-consuming and tiring to do so.

Indirect rebound effects have also been observed in relation to ICT services that seek to reduce transportation. For example, in the cases of teleshopping, telecommuting and teleconferencing "a substantial part of the transport savings are nullified by increased transport for other purposes such as shopping and increased transport by other family members" [48, p. 132]. Case studies suggest that the highest rebound is found in Denmark (73\%): although $105 \mathrm{~km}$ could be saved in weekly commuting, 77 extra kilometers were driven. In the Netherlands, 42 extra kilometers were driven compared to 98 saved (hence a $43 \%$ rebound effect). The lowest rebound effects were found in Italy $(14 \%, 242 \mathrm{~km}$ saved vs. $33 \mathrm{~km}$ extra) and Germany $(19 \%, 283 \mathrm{~km}$ saved vs. $53 \mathrm{~km}$ extra).

In the logistics sector, electronic vehicle management systems are supposed to improve capacity utilization. Studying their impact on the load factor of heavy trucks, authors find evidence of a rebound effect on fronthaul movements, measured by a reduction of the load factor by about $8 \%$ [49].

Other indirect rebound effects related to ICT are plausible, although they have not been empirically studied thus far. Examples are those related to information and knowledge. Since ICT enable more efficient ways of handling information, "individual efforts to access and exchange information is lower than before" [9, p. 91]. This decreases companies' internal price of information work, and increases demand for information, causing people to waste time filing reports. This increased efficiency of distributing information also benefits researchers: thanks to online databases, the number of journal articles has boomed. For example, it was estimated that by the end of 2008 about 50 million articles had been published in the world [50]. Digital technologies also eased the creation of journals, including open access ones, making it harder for researchers to follow up scientific discoveries. It even impacted academic evaluation procedures: "The Internet has not only reduced the cost and effort of conducting peer review through highly automated Web-based management systems, it has provided a great deal of flexibility in how peer review can be conducted" [51]. This phenomenon has gone hand in hand with the diffusion of procedures to evaluate researchers based on the quality and number of publications. Studies show that when such measures are put in place, the impact factor decreases [52], for example because instead of publishing one single paper in a very good journal with a longer evaluation process, researchers tend to send several papers to journals with shorter publishing 
times but lower impact factors. As a consequence of this overflow of knowledge diffusion, although the efficiency of carrying out research has increased tremendously it has become more difficult to assimilate knowledge because there is so much of it. Indeed, "a growing number of available and potentially interesting goods and pieces of information shortens the span of time that can be devoted to each particular object," and as a consequence "the amount of time we can allot to the dutiful perusal of an academic journal decreases in lockstep with the increase in the number of relevant journals" [53, p. 125]. To conclude on information-related rebound effects, as Hilty puts it: "Acceleration is certainly the most significant effect of ICT, the very heart of its potential for societal change" [9, p. 69]. Within companies, ICT enabled people to process information more efficiently, but at the same time "the demand for internal reporting has increased with the development of IT infrastructure in many organizations to a degree that affects the productivity of the organization" [54, p. 27]. Paradoxically, "although we constantly save time by using better and speedier technology, in the end we do not have more time than before, even less perhaps" [55, p. 295]. Hilty conducted an experiment on the use of PCs in order to understand whether new versions of operating systems had generated rebound effects. He concluded that "changing over to a faster computer running newer software does not necessarily lead to higher work efficiency" [9, p. 89]. This can be explained by new functionalities added by software developers, who tend to overlook software efficiency, and by "software bloating." Besides, "technological change of a time-saving nature can have a large influence on energy use as many time-saving devices (for example, faster modes of transport) require an increase in energy consumption that is frequently reinforced by a 'rebound effect with respect to time"' [27, p. 119].

\subsection{Economy-Wide Rebound Effects}

Economy-wide rebound effects appear when declining costs of a key resource induce a reduction in the prices of intermediate and final goods throughout the economy, and cause structural changes in production patterns and consumption habits.

Unfortunately, to our knowledge no study has sought to evaluate those effects in the case of ICT. An interesting discussion in relation to the economy-wide rebound effects caused by ICT is proposed by Sorrell [8]. In a critical assessment of the work of Brookes and Saunders, he suggests that they do not "distinguish the energyefficiency improvements associated with general purpose technologies and other forms of energy-efficiency improvements." [10, p. 1467] According to Sorrell, economy-wide rebound effects are likely to be large in the case of energy efficiency improvements associated with general purpose technologies. On the other hand, for technologies with smaller economy-wide effects, "Jevons' Paradox seems less likely to hold," as in the case of dedicated energy-efficiency technologies (ibid.). Therefore, if ICT are indeed energy-efficiency technologies, because they are general purpose technologies their environmental benefits are likely to be absorbed by economy-wide rebound effects.

Finally, as a suggestion for future research we would like to propose a new type of economy-wide rebound effect that has not been investigated yet. As general purpose 
technologies, ICT have had positive economic impacts in many economic sectors. The diffusion of ICT has also taken place in the financial sector. Without ICT world financial markets would not be interconnected and speculative activities such as high frequency trading would hardly be possible. The diffusion of ICT in the financial sector is having economy-wide effects that can offset the economic benefits of ICT. For example, ICT contribute to the financialization of our economies that deters innovation [56], including environmental innovation \{Bohl, 2013 \#3227\}. Given their importance in the financial sector, ICT also played a role in the financial crisis, which according to some estimates caused economic losses of "at least a year's worth of U.S. economic output" (more than 14,000 billion dollars) [57]. We can thus argue that the economic benefits of ICT are offset by the losses caused by their diffusion in the financial sector, which represents an economy-wide rebound effect.

\section{Conclusion}

In this paper we have discussed the rebound effects related to ICT. Although the number of academic papers evaluating rebound effects in other sectors such as transportation or buildings has increased greatly over the past few years, the ICT sector remains underinvestigated. This is despite the fact that existing papers all point out that ICT are subject to important rebound effects of all kinds (energy, time, and knowledge-related), notably because ICT are general purpose technologies that can generate high resource savings throughout the entire economy and society. Although more research is needed to evaluate those rebound effects, some lessons can be learned about how to overcome them.

First, efficiency strategies should not rely exclusively on technological change. As Hilty puts it: "In general terms, an efficiency strategy must always be accompanied by a sufficiency strategy" [9, p. 72]. Other authors have also argued in favor of such behavioral changes on the consumer side [58-61]. Also, general awareness of rebound effects should be increased [62], including limitations of the concept, especially at the macro level. Van den Bergh suggests carrying out systematic "energy/environmental rebound assessments" of important energy conservation projects or strategies, just as any large investment project requires an environmental impact assessment [63]. Integrating rebound effects in energy efficiency evaluations is one solution [64], and integrating them in life cycle assessments is another [65], as has been attempted by Andersen for renewable energy [18]. Finally, efficiency evaluations need to stop focusing on individual products and look at the broader picture, even if the difficulty of finding data makes this challenging. In the case of spam, massive information pollution due to low email costs, Mike Berners-Lee (the brother of Tim who founded the World Wide Web) suggests taxing by one cent per email, since in terms of energy intensity "e-mail is great individually, but it's terrible in the aggregate because there's so much of it" [66, p. 65]. Combining technological efficiency measures with pollution capping would "create incentives that would spur demandside efficiencies to match those already realized on the supply side" (ibid.). Besides, policies and strategies could be developed to support energy-aware ICT by design, as 
suggested by Ricciardi et al. for the Internet [67]. This would enable ICT to control for their energy impacts from the design stage, in a similar fashion to what has been done with "privacy-by-design" technologies [68].

Beyond the technicality of their evaluation, rebound effects should be perceived as indicators of destructive contradictions in our socioeconomic systems. Studying them enables us to better understand these contradictions, and to imagine means to overcome them. Some argue that if they are controlled, technologies could support the absolute decoupling between increased wellbeing and worsening ecological impacts [63]. Otherwise, only partial decoupling might be achieved, at best [69]. Solutions to combat rebound effects are outside the scope of this chapter. Yet we can sense that they require profound changes in our production systems and consumption patterns in order to achieve a sustainable transition of human societies.

\section{References}

1. ADEME: Chiffres clés (Climat, Air et Energie) - Edition 2013 (2014)

2. Herring, H.: Does energy efficiency save energy? Power Economics 4(4), 27 (2000)

3. Herring, H.: Energy efficiency: A critical view. Energy 31(1), 10-20 (2006)

4. Alcott, B.: Jevons' paradox. Ecological Economics 54(1), 9-21 (2005)

5. Polimeni, J.M.: Empirical evidence for the Jevons paradox. In: Polimeni, J.M., Mayumi, K., Giampietro, M., Alcott, B. (eds.) The Jevons paradox and the myth of resource efficiency improvements. pp. 141-171. Earthscan, (2008)

6. Missemer, A.: William Stanley Jevons' The Coal Question (1865), beyond the rebound effect. Ecological Economics 82, 97-103 (2012)

7. Khazzoom, J. D. (1980). "Economic implications of mandated

8. Sorrell, S.: Jevons' Paradox revisited: The evidence for backfire from improved energy efficiency. Energy Policy 37(4), 1456-1469 (2009)

9. Hilty, L.M.: Information technology and sustainability: Essays on the relationships between information technology and sustainable development. Books on Demand, Norderstedt (2008)

10. Berkhout, F., Hertin, J.: Impacts of information and communication technologies on environmental sustainability: Speculations and evidence, vol. 21. OECD report, University of Sussex, Brighton (2001)

11. Kennedy, S., Hill, S.: Could stereotype rebound affect aid advertising campaigns? International Journal of Nonprofit \& Voluntary Sector Marketing 14(2), 111-123 (2009)

12. Global View, Bio Intelligence Service, Ecologic: Addressing the rebound effect. Interim Report to the European Commission (2011)

13. Berkhout, P.H.G., Muskens, J.C., W. Velthuijsen, J.: Defining the rebound effect. Energy Policy 28(6-7), 425-432 (2000)

14. Greening, A.L., Greene, D.L., Difiglio, C.: Energy efficiency and consumption, the rebound effect: A survey. Energy Policy 28(6-7), 389-401 (2000)

15. Sorrell, S., Dimitropoulos, J.: The rebound effect: Microeconomic definitions, limitations and extensions. Ecological Economics 65(3), 636-649 (2008)

16. Bentzen, J.: Estimating the rebound effect in US manufacturing energy consumption. Energy Economics 26(1), 123-134 (2004) 
17. Schipper, L., Grubb, M.: On the rebound? Feedback between energy intensities and energy uses in IEA countries. Energy Policy 28(6-7), 367-388 (2000)

18. Andersen, O.: Rebound effects. In: Andersen, O. (ed.) Unintended consequences of renewable energy. Green energy and technology, pp. 19-33. Springer, London (2013)

19. Youtie, J., Iacopetta, M., Graham, S.: Assessing the nature of nanotechnology: can we uncover an emerging general purpose technology? The Journal of Technology Transfer 33(3), 315-329 (2008)

20. Røpke, I.: The unsustainable directionality of innovation - The example of the broadband transition. Research Policy 41(9), 1631-1642 (2012)

21. Jovanovic, B., Rousseau, P.L.: General Purpose Technologies. In: Philippe, A., Steven, N.D. (eds.) Handbook of Economic Growth, vol. Volume 1, Part B. vol. Chapter 18, pp. 1181-1224. Elsevier, London (2005)

22. BIO Intelligence Service: Impacts of ICT on energy efficiency. Report to DG INFSO (2008)

23. European energy efficiency plan. http://ec.europa.eu/energy/efficiency/action_plan/action plan_en.htm.

24. GeSI: Smart 2020: Enabling the low carbon economy in the information age. (2008)

25. Antunes, C.H.: Energy efficiency for a more sustainable world. Energy Policy 67(0), 1-3 (2014)

26. Cho, Y., Lee, J., Kim, T.-Y.: The impact of ICT investment and energy price on industrial electricity demand: Dynamic growth model approach. Energy Policy 35(9), 4730-4738 (2007)

27. Binswanger, M.: Technological progress and sustainable development: what about the rebound effect? Ecological Economics 36(1), 119-132 (2001)

28. Sorrell, S.: The evidence for direct rebound effects. In: Sorrell, S., Herring, H. (eds.) Energy efficiency and sustainable consumption: The rebound effect. pp. 23-46. Palgrave Macmillan, Basingstoke (2009)

29. Coroama, V.C., Moberg, A., Hilty, L.M.: Dematerialization through Electronic Media? In: Hilty, L.M., Aebischer, B. (eds.) ICT Innovations for Sustainability. Advances in Intelligent Systems and Computing. Springer Springer International (2014)

30. Aebischer, B., Hilty, L.M.: The Energy Demand of ICT: A Historical Perspective and Current Methodological Challenges. In: Hilty, L.M., Aebischer, B. (eds.) ICT Innovations for Sustainability. Advances in Intelligent Systems and Computing. Springer Springer International (2014)

31. Kaeslin, H.: Semiconductor Technology and the Energy Efficiency of ICT. In: Hilty, L.M., Aebischer, B. (eds.) ICT Innovations for Sustainability. Advances in Intelligent Systems and Computing. Springer Springer International (2014)

32. Williams, E.D.: Environmental impacts of microchip manufacture. Thin Solid Films 461(1), 2-6 (2004)

33. Köhler, A., Erdmann, L.: Expected environmental impacts of pervasive computing. Human and Ecological Risk Assessment: An International Journal 10(5), 831-852 (2004)

34. Mercep, L., Buitkamp, C., Stähle, H., Spiegelberg, G., Knoll, A., Lienkamp, M.: The Innotruck case study on a holistic approach to electric mobility. In: Wellnitz, J., Subic, A., Trufin, R. (eds.) Sustainable automotive technologies 2013. Lecture Notes in Mobility, pp. 277-287. Springer International Publishing, (2014)

35. Demarthon, F., Delbecq, D., Fléchet, G.: The big data revolution. CNRS international magazine 28, 20-27 (2013)

36. Hilbert, M., López, P.: The World's Technological Capacity to Store, Communicate, and Compute Information. Science 332(6025), 60-65 (2011) 
37. Kogge, P.: The tops in flops. Spectrum, IEEE 48(2), 48-54 (2011)

38. Wolfe, M.: Beyond "green buildings": Exploring the effects of Jevons' paradox on the sustainability of archival practices. Arch Sci 12(1), 35-50 (2012)

39. Herring, H., Roy, R.: Sustainable services, electronic education and the rebound effect. Environmental Impact Assessment Review 22(5), 525-542 (2002)

40. Caird, S., Lane, A., Swithenby, E.: ICTs and the design of sustainable higher education teaching models: An environmental assessment of UK courses. In: Caeiro, S., Filho, W.L., Jabbour, C., Azeiteiro, U.M. (eds.) Sustainability assessment tools in higher education institutions. pp. 375-385. Springer International Publishing, (2013)

41. Hoogeveen, M.J., Reijnders, L.: E-commerce, paper and energy use: a case study concerning a Dutch electronic computer retailer. International Journal of Global Energy Issues 18(2/3/4), 294-301 (2002)

42. Yi, L., Thomas, H.R.: A review of research on the environmental impact of e-business and ICT. Environment International 33(6), 841-849 (2007)

43. Fichter, K.: E-commerce: Sorting out the environmental consequences. Journal of Industrial Ecology 6(2), 25-41 (2002)

44. Fuchs, C.: The implications of new information and communication technologies for sustainability. Environ Dev Sustain 10(3), 291-309 (2008)

45. Hilty, L.M., Arnfalk, P., Erdmann, L., Goodman, J., Lehmann, M., Wäger, P.A.: The relevance of information and communication technologies for environmental sustainability - A prospective simulation study. Environmental Modelling \& Software 21(11), 1618-1629 (2006)

46. Gardiner, B.: How Smart ICT will find you a parking space. Business Reporter (2013). http://business-reporter.co.uk/2013/01/how-smart-ict-will-find-you-a-parking-space

47. Green, J.: Smart Parking coming to France. Smart Mobility Management (2013). http://www.smart-mobilitymanagement.com/smart_parking_coming_to_france_54781-en425-185015.html

48. Falch, M.: Environmental Impact of ICT on the Transport Sector. In: Hadjiantonis, A., Stiller, B. (eds.) Telecommunication Economics, vol. 7216. Lecture Notes in Computer Science, pp. 126-137. Springer Berlin Heidelberg, (2012)

49. Barla, P., Bolduc, D., Boucher, N., Watters, J.: Information technology and efficiency in trucking. Canadian Journal of Economics 43(1), 254-279 (2010)

50. Jinha, A.E.: Article 50 million: an estimate of the number of scholarly articles in existence. Learned Publishing 23(3), 258-263 (2010)

51. Solomon, D.J.: The Role of Peer Review for Scholarly Journals in the Information Age Journal of Electronic Publishing 10(1) (2007)

52. Gossart, C., Özman, M.: Co-authorship networks in social sciences: The case of Turkey. Scientometrics 78(2), 323-345 (2009)

53. Rosa, H.: Social acceleration: A new theory of modernity. Columbia University Press, (2013)

54. Hilty, L.M, Köhler, A., Schéele, F., Zah, R., Ruddy, T.: Rebound effects of progress in information technology. Poiesis Prax 4(1), 19-38 (2006)

55. Hörning, K.H., Ahrens, D., Gerhard, A.: Do Technologies have Time?: New Practices of Time and the Transformation of Communication Technologies. Time \& Society 8(2-3), 293-308 (1999)

56. Lazonick, W.: From Innovation to Financialization: How Shareholder Value is Destroying the U.S. Economy. In: Wolfson, M.H., Epstein, G.A. (eds.) The Handbook of the Political Economy of Financial Crises. pp. 491-511. Oxford University Press, (2013) 
57. Gongloff, M.: The Financial Crisis Cost More Than $\$ 14$ Trillion: Dallas Fed Study. The Huffington Post (2013). http://www.huffingtonpost.com/2013/07/30/financial-crisis-costfed-study_n_3676118.html

58. Steinberger, J.K., van Niel, J., Bourg, D.: Profiting from negawatts: Reducing absolute consumption and emissions through a performance-based energy economy. Energy Policy 37(1), 361-370 (2009)

59. Murray, C.K.: What if consumers decided to all 'go green'? Environmental rebound effects from consumption decisions. Energy Policy 54, 240-256 (2013)

60. Throne-Holst, H., Stø, E., Strandbakken, P.: The role of consumption and consumers in zero emission strategies. Journal of Cleaner Production 15(13/14), 1328-1336 (2007)

61. Passey, R., MacGill, I.: Energy sales targets: An alternative to White Certificate schemes. Energy Policy 37(6), 2310-2317 (2009)

62. Shay, S.: Bigfoot. Technology Review 111(4), M7-M7 (2008)

63. van den Bergh, J.C.J.M.: Energy conservation more effective with rebound policy. Environmental and Resource Economics 48(1), 43-58 (2011)

64. Vine, E., Hall, N., Keating, K., Kushler, M., Prahl, R.: Emerging evaluation issues: Persistence, behavior, rebound, and policy. Energy Efficiency 6(2), 329-339 (2013)

65. Madjar, M., Ozawa, T.: Happiness and sustainable consumption: Psychological and physical rebound effects at work in a tool for sustainable design. The International Journal of Life Cycle Assessment 11(1), 105-115 (2006)

66. Nowak, P.: Beware the rebound effect. Corporate Knights Magazine 11(1), 65 (2012)

67. Ricciardi, S., Careglio, D., Santos-Boada, G., Solé-Pareta, J., Fiore, U., Palmieri, F.: Towards an energy-aware Internet: modeling a cross-layer optimization approach. Telecommun Syst 52(2), 1247-1268 (2013)

68. Shapiro, S.S.: Privacy by design: Moving from art to practice. Communications of the ACM 53(6), 27-29 (2010)

69. Irrek, W.: How to Reduce the Rebound Effect? In: Bleischwitz, R., Welfens, P.J.J., Zhang, Z. (eds.) International Economics of Resource Efficiency. pp. 279-285. Physica-Verlag HD, Heidelberg (2011) 